\title{
Efficiency of steam reheating in heat recovery steam generator at thermal power plant with gas turbine topping
}

\author{
Olga Romashova ${ }^{1, *}$, Aleksandr Minor ${ }^{1}$, Vladimir Martyshev ${ }^{1}$, Aleksandr Tubolev ${ }^{1}$, and \\ Aleksandra Katalevskaya ${ }^{1}$ \\ ${ }^{1}$ National Research Tomsk Polytechnic University, 634050 Tomsk, Russia
}

\begin{abstract}
Possibility of using alternative option to the displacement of regenerative heating is analyzed in this paper: application of heat recovery steam generator's (HRSG) thermal power for reheating of working medium that has passed steam turbine.
\end{abstract}

\section{Introduction}

Technical re-equipment and modernization of existing Thermal Power Plants (TPPs) with implementation of combined-cycle technologies lead to significant reduction in specific consumption of reference fuel for electricity generation. At the same time, indices of TPPs thermal efficiency after modernization are mainly determined by adopted technical solutions [1-4].

Along with the most efficient, but also more costly option for constructing new modern Combined Cycle Power Plants (CCPPs) at the site of an old TPP, there is a transition to CCPP with application of operating stations equipment. In principle, there are two options: 1) installation of gas turbine (GT) and HRSG in existing building with dismantling of existing steam boiler; 2) integration of GT into the thermal scheme of steam-power unit (at coal-fired power plants where natural gas is used as the second fuel). In many cases, option 2 is more preferable, since it allows full utilization of existing plant infrastructure and reduction of investment costs.

There are three possibilities in principle for integrating GT in cycle arrangement: 1) application of GT exhaust gases as oxidizer for fuel combustion in steam boiler; 2) inclusion of GT in a parallel scheme for production of steam in HRSG with its further supply to steam line along with the working fluid of steam boilers; 3) the use of GT exhaust gases warmth for heating of feed water and condensate.

Schemes with heating of feed water and condensate in HRSG are most widespread and have been called GT topping with displacement of regenerative heating [5-7]. Disadvantage of such modernization for TPPs is a significant deterioration of steam turbine plant (STP) thermal efficiency: the share of heat losses in condenser increases, consumption of main

\footnotetext{
Corresponding author: roma@tpu.ru
} 
steam decreases compared to the nominal value due to limitation of steam passage to condenser with corresponding drop of STP electrical power.

Possibility of using alternative option to the displacement of regenerative heating is analyzed in this paper: application of heat recovery steam generator's (HRSG) thermal power for reheating of working medium that has passed steam turbine.

\section{HRSG options for displacing steam reheating and regenerative heating}

Thermal efficiency of CCPP schemes with displacement of steam reheating and regenerative heating from steam-turbine part for different options of HRSG heat application is compared: scheme 1 (Fig. 1) - displacement of steam reheating from steam boiler; scheme 2 (Fig. 2) - partial displacement of regenerative heating (high-pressure heaters (HPHs)); scheme 3 (Fig. 3) - displacement of steam reheating with partial displacement of regenerative heating; scheme 4 (Fig. 4) - complete displacement of regenerative heating.

As an example, CCPP calculations are applied to steam-turbine power unit with steam reheating, for which the initial data is presented in Table 1. For the initial scheme (scheme 0 ), efficiency of electricity production is $43 \%$, thermal load of steam reheating is $\mathrm{Q}_{\mathrm{sr}}=39$ MW, thermal load of HPHs is assumed equal to $\mathrm{Q}_{\mathrm{sr}}$, thermal load of low-pressure heaters (LPHs) is $27 \mathrm{MW}$, steam flow to condenser is $55.7 \mathrm{~kg} / \mathrm{s}$.

Table 1. Initial data for STP scheme calculation.

\begin{tabular}{|c|c|c|c|c|c|c|c|c|c|}
\hline $\begin{array}{c}\text { parameters of } \\
\text { the main } \\
\text { steam }\end{array}$ & $\begin{array}{c}\text { parameters of } \\
\text { reheated } \\
\text { steam }\end{array}$ & $\begin{array}{c}\text { deaera } \\
\text { tor } \\
\text { pressu } \\
\text { re }\end{array}$ & $\begin{array}{c}\text { tempe } \\
\text { rature } \\
\text { of } \\
\text { feed } \\
\text { water }\end{array}$ & $\begin{array}{c}\text { pressure } \\
\text { in the } \\
\text { extractio } \\
\text { n for } \\
\text { low- } \\
\text { pressure } \\
\text { heater }\end{array}$ & $\begin{array}{c}\text { condens } \\
\text { er } \\
\text { pressure }\end{array}$ & $\begin{array}{c}\text { electri } \\
\text { cal } \\
\text { power }\end{array}$ & $\begin{array}{c}\text { heating in } \\
\text { deaerator }\end{array}$ & \\
\hline$P_{0}$ & $t_{0}$ & $P_{s r}$ & $t_{s r}$ & $P_{d}$ & $t_{f w}$ & $P_{e x}^{l p}$ & $P_{c}$ & $N_{E}$ & $\Delta t_{d}$ \\
\hline $\mathrm{MPa}$ & ${ }^{\circ} \mathrm{C}$ & $\mathrm{MPa}$ & ${ }^{\circ} \mathrm{C}$ & $\mathrm{MPa}$ & ${ }^{\circ} \mathrm{C}$ & $\mathrm{MPa}$ & $\mathrm{MPa}$ & $\mathrm{MW}$ & ${ }^{\circ} \mathrm{C}$ \\
\hline 14 & 550 & 2.1 & 550 & 0.6 & 260 & 0.46 & 0.005 & 100 & 10 \\
\hline
\end{tabular}

Additional initial data for calculation is taken from the prototype - GT Siemens V 64.3A: exhaust gas temperature is $571{ }^{\circ} \mathrm{C}$, gas temperature before $\mathrm{GT}$ is $1315^{\circ} \mathrm{C}$, compression ratio in compressor is 16.2 [8]. In all options pressures in the steam tapping are recalculated using Stodola-Flugel dependence according to the methods of STP variable-load operation. Passage of steam through the last stages is maintained equal to its value in the initial scheme.

For scheme 1, thermal power of HRSG is considered equal to the thermal load of steam reheating in the initial scheme.

For scheme 2, passage of steam through the last stages is limited; it is taken from the initial scheme. Thermal power of HRSG remains unchanged compared to the first option and corresponds to the thermal load of initial circuit high-pressure heater.

Schemes 3 and 4 allow lowering the temperature of exhaust gases due to more complete utilization of HRSG heat. For these schemes, temperature of waste gases is assumed to be $100^{\circ} \mathrm{C}$.

Combination of two alternative options is applied at scheme 3. Gases flowrates are determined from steam reheater heat balance in HRSG. Temperature of feed water remains the same. Heating of water in deaerator does not change compared to the initial scheme. 
For scheme 4, HRSG completely replaces regenerative heaters. Its thermal power corresponds to the total heat load of HPHs and LPHs. Consumption and temperature of the gases in HRSG at the outlet from HPH are determined from the heat balance equations.

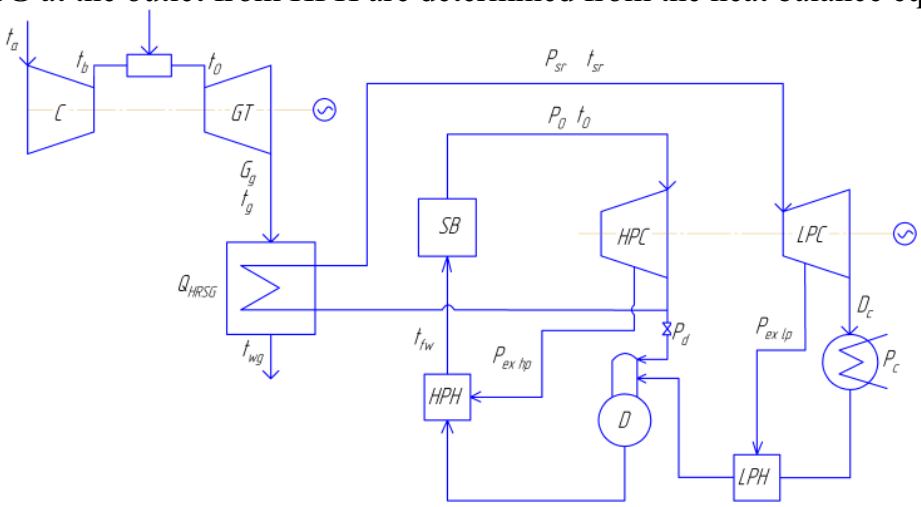

Fig. 1. Scheme 1 (steam reheating displacement from steam boiler).

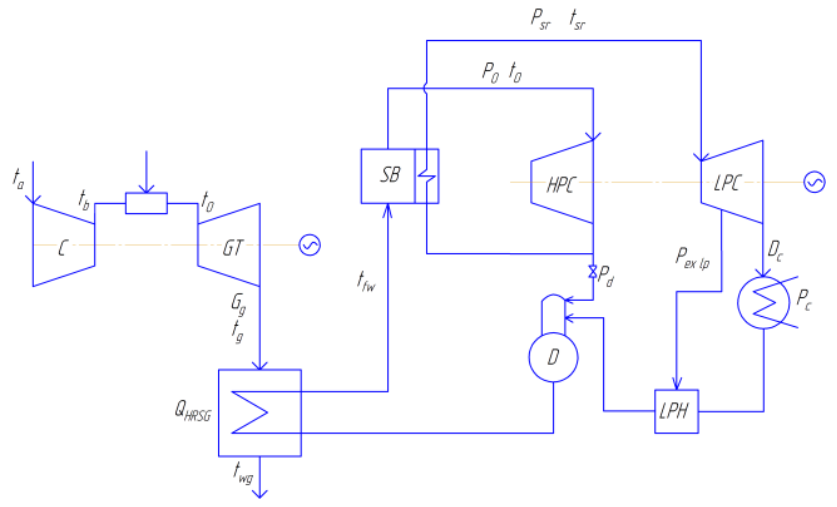

Fig. 2. Scheme 2 (partial regenerative heating (HPHs) displacement).

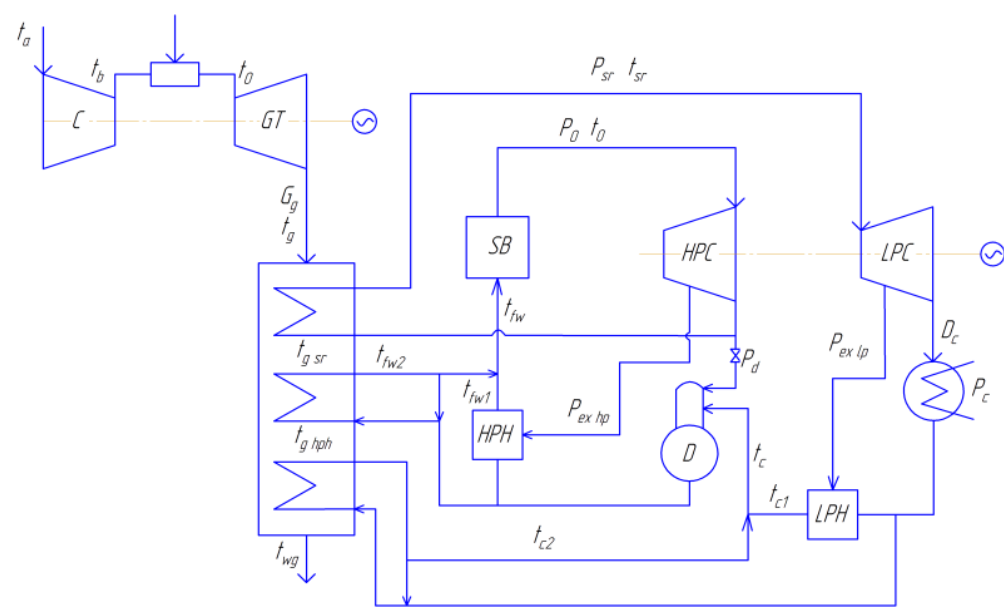

Fig. 3. Scheme 3 (steam reheating displacement from steam boiler and partial displacement of regenerative heating). 


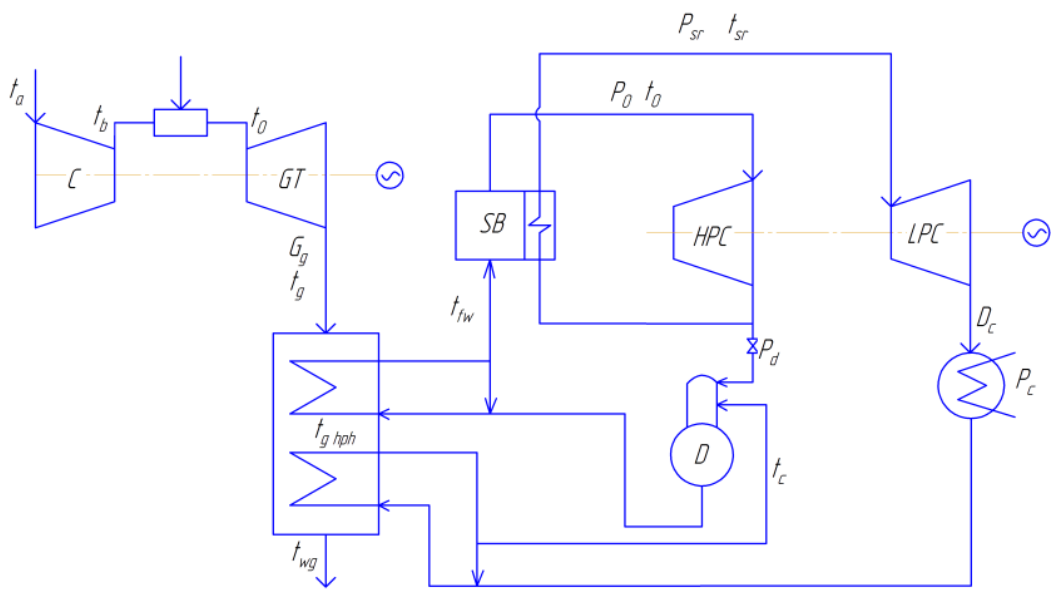

Fig.4. Scheme 4 (complete displacement of regenerative heating).

\section{Results of calculations}

Results of GT-toppings various options comparison are presented in Fig. 5-7.

Components of the total delivered heat of CCPP binary cycle are shown in Fig. 5 $\mathrm{Q}_{1}=\mathrm{Q}_{\mathrm{SB}}+\mathrm{Q}_{\mathrm{HRSG}}$ (steam boiler plus $\mathrm{HRSG}$ ) for all compared options, where $\overline{\mathrm{N}}_{\mathrm{E} \mathrm{STP}}=\mathrm{N}_{\mathrm{E} \mathrm{STP}} / \mathrm{Q}_{1} ; \overline{\mathrm{N}}_{\mathrm{E} \mathrm{GT}}=\mathrm{N}_{\mathrm{E} \mathrm{GT}} / \mathrm{Q}_{1}, \overline{\mathrm{Q}}_{\mathrm{WH}}=\mathrm{Q}_{\mathrm{WH}} / \mathrm{Q}_{1}, \overline{\mathrm{Q}}_{\mathrm{C}}=\mathrm{Q}_{\mathrm{C}} / \mathrm{Q}_{1}$ - proportions of steam turbine electric power, gas turbine, waste heat losses and losses in condenser. The largest losses of heat in condenser belong to schemes 2 and 4. Displacement of HPH leads to an increase in losses in the cold source by almost $23 \%$ in comparison with the initial scheme of STP, and complete displacement - by almost $50 \%$.

Option of HRSG heat power application for steam reheating with complete preservation of regenerative heating (scheme 1) keeps heat loss in condenser at the nominal level. However, the losses of heat with exhaust gases (up to $15 \%$ from $\mathrm{Q}_{1}$ of the total balance against (3-5)\% for schemes 2 and 4). The reason is increased temperature of exhaust gases, which is determined by the temperature of steam in the cold thread of the steam reheating. Transition to scheme 3 with combination of HRSG application for steam reheating and regenerative heating leads to decrease in heat loss with exhaust gases to the minimal values with a certain increase in heat loss in condenser compared to STP scheme.

Fig. 6 represents graphical comparison of CCPP electrical efficiency values for the studied options. The greatest thermal efficiency has scheme with displacement of steam reheating and regenerative heating (scheme 3) - an increase in efficiency is $14.7 \%$ compared with initial scheme. The other schemes differ little from each other according to thermal efficiency. The increase in absolute electrical efficiency for scheme 2 is $5.5 \%$, scheme $4-6.0 \%$, scheme $1-7 \%$.

The greatest value of CCPP electric power is characteristic of scheme 1 because of nominal electric load preservation of steam turbine in comparison with other options (Fig. 7). Electric power values of gas turbine for schemes 3 and 4 are comparable due to the close values of working medium flow rate of gas turbine cycle. The smallest electric capacity of steam-power cycle belongs to scheme 4 because of the lowest steam consumption per turbine. 
Decrease in the efficiency of steam boiler due to the change in its operating mode is estimated in all schemes approximately the same, since new values of steam boiler thermal capacity in CCPP composition lie in all options in the range (70-85)\% of the nominal load.

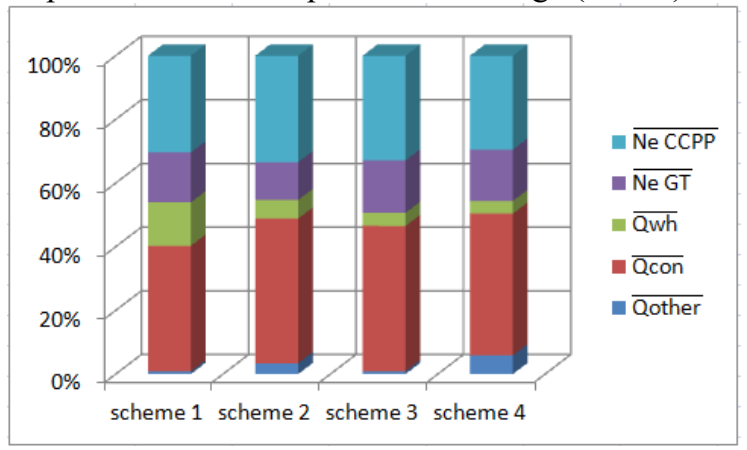

Fig. 5. Components of delivered heat in CCPP cycle.

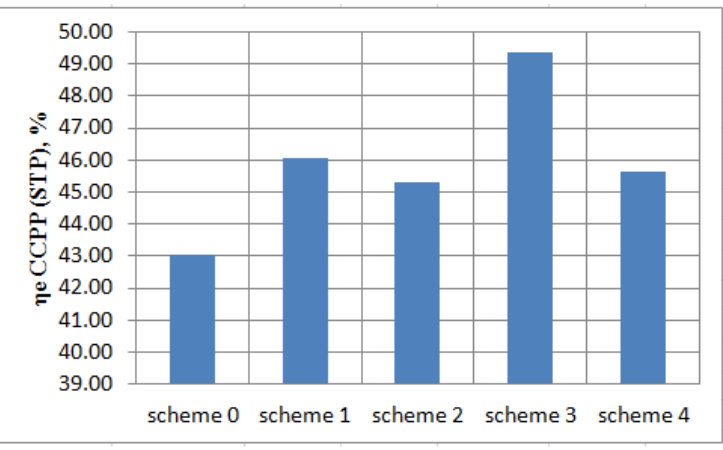

Fig. 6. Absolute electrical efficiency of CCPP (STP).

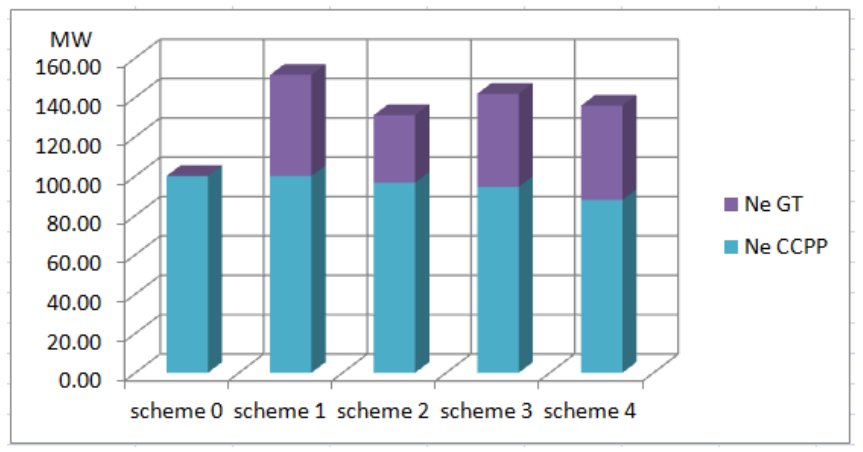

Fig. 7. Electrical capacity of CCPP (STP).

\section{Choice of the optimum steam reheating pressure in the HRSG}

Previous calculations were conducted at optimal design pressure of steam cycle reheating, which for STP scheme with single steam reheating is (15-20) \% of the initial $\mathrm{P}_{0}$.

This paper presents analysis of factors influencing the choice of optimal value of steam reheating pressure in CCPP schemes, as well as calculation of optimal value for the simplest scheme of STP (without regenerative heating) and for scheme 3. 
For the simplest cycle of STP with steam reheating in HRSG, optimal steam reheating pressure is insignificant portion of $\mathrm{P}_{0}-(1.6-2) \%$ (Fig. 8). At the same time, as the pressure of superheating increases, temperature of exhaust gases continuously increases, because it is determined by steam temperature in cold train of steam reheating (Fig. 9) and at an optimal value greatly exceeds minimal possible value (more than $150^{\circ} \mathrm{C}$ against $80-100^{\circ} \mathrm{C}$ ).

In the design of STP for scheme 3 the choice of optimal steam reheating pressure depends on assigned temperature of exhaust gases. With a decrease in exhaust gases temperature, optimal values of steam reheating pressure shift towards higher magnitudes (Fig. 11). At the same time, absolute electrical efficiency of CCPP is also increasing (Fig. $12)$. In the range of assigned values for exhaust gases temperature $(80-120)^{\circ} \mathrm{C}$, optimal steam reheating pressure is $(24-27) \%$ of $\mathrm{P}_{\mathrm{o}}$ (Fig. 10), which exceeds maximal values of optimal parameters range of steam reheating pressure in traditional schemes of STP.

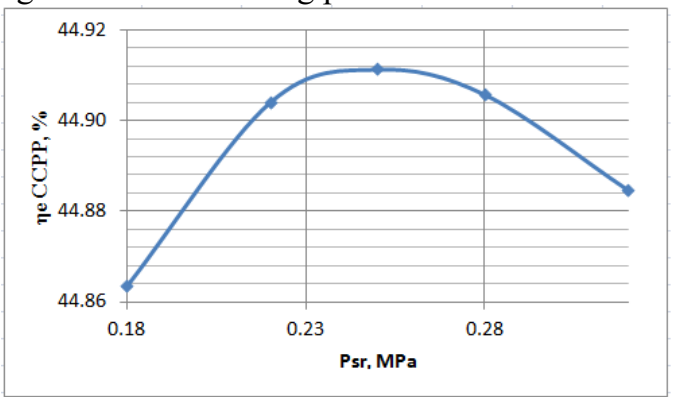

Fig. 8. Dependence of absolute electrical efficiency for the simplest cycle of STP with steam reheating in HRSG from SR pressure.

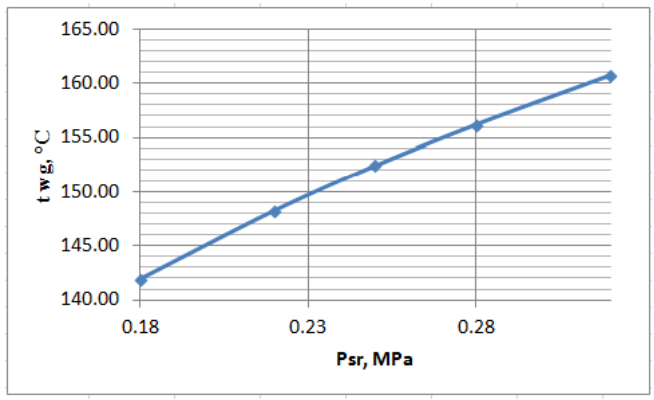

Fig. 9. Dependence of exhaust gases temperature for the simplest cycle of STP with steam reheating in HRSG from SR pressure.

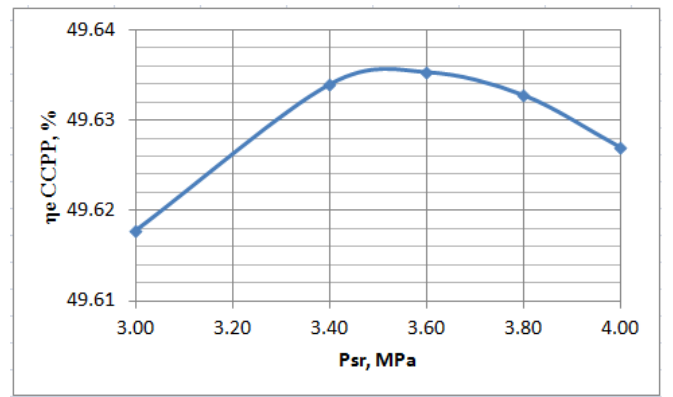

Fig.10. Dependence of absolute electrical efficiency of CCPP from SR pressure (scheme 3$)\left(t_{\mathrm{wg}}=\right.$ $\left.100^{\circ} \mathrm{C}\right)$. 


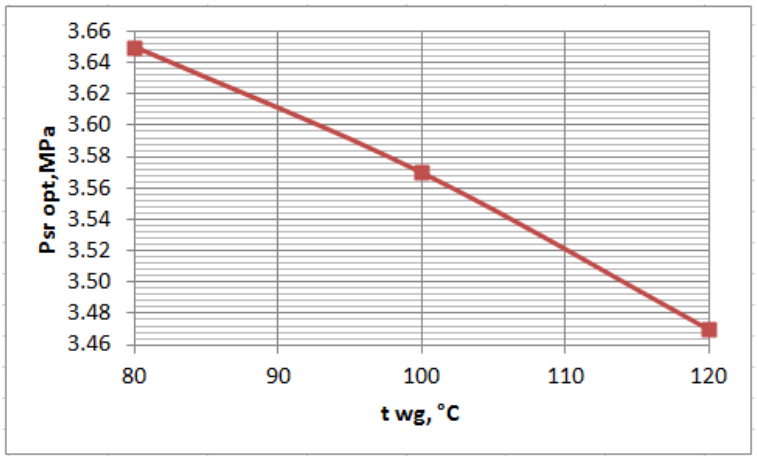

Fig.11. Dependence of optimal steam reheating pressure from exhaust gases temperature (scheme $3)$.

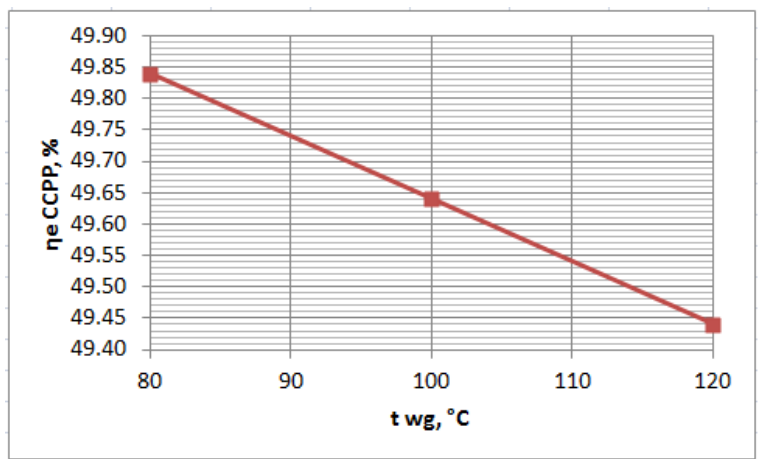

Fig.12. Dependence of absolute electrical efficiency of CCPP from exhaust gases temperature at optimal steam reheating pressure (scheme 3 ).

\section{Conclusion}

To sum up:

- displacement of HPH from steam turbine plant leads to an increase of heat losses in condenser by $24 \%$ compared with initial scheme of STP; complete replacement of regenerative heating increases losses by $50 \%$. Steam flowrate to the turbine decreases, which leads to a decrease in electrical capacity.

- increase in CCPP efficiency, in comparison with initial option when HPH is displaced, is $5.5 \%$. The use of regenerative heating complete displacement leads to insignificant increase of efficiency (by 6\%) despite the decrease of exhaust gases temperature.

- displacement of steam reheating from steam boiler makes it possible to reduce heat losses in condenser in comparison with displacement of regenerative heating and to keep steam flowrate to the turbine at the level of nominal value.

- efficiency of CCPP for scheme with displacement of steam reheating is $7 \%$ higher than efficiency of the initial STP. At the same time, heat losses with exhaust gases reach maximal value in comparison with other options because of increased temperature of the gases at HRSG's cold end, which is determined by steam temperature in the cold train of steam reheating.

- the greatest increase in efficiency (up to 15\%) is provided by combination of steam reheating displacement method with partial displacement of regenerative heating. 
- optimal pressure of steam reheating in HRSG for the simplest cycle of STP is (1.6$2.0) \%$ of the initial pressure, which is significantly lower than these values for single reheating scheme in STP (15-20)\%.

- in the design of CCPP with full displacement of steam reheating and partial regenerative heating from steam turbine part to HRSG the choice of optimal steam reheating pressure depends on assigned temperature of exhaust gases. With decrease of exhaust gases temperature, at equal other conditions, optimal pressure and efficiency of CCPP increase. In the range of exhaust gases assigned temperatures $(80-120)^{\circ} \mathrm{C}$ optimal steam reheating pressure is in the range of $(24-27) \%$ of $P_{o}$.

\section{References}

1. S.V. Tsanev, C.V. Tsaneva, V.D. Burov, A.N. Remezov, Gas turbine and combinedcycle plants of thermal power plants (Publishing House MEI, Moscow, 2006)

2. N. Galashov, S. Tsibulskii, A. Matveev, V. Masjuk, EPJ Web Conf. 110, 01019 (2016)

3. Galashov, S. Tsibulskiy, A. Kiselev, MATEC Web Conf. 72, 01029 (2016)

4. A.I. Gabdullina, N.N. Galashov, S.A. Tsbuskiy, D.V. Melnikov, I.A. Asanov A.S. Kiselev, MATEC Web Conf. 91, 01004 (2017)

5. P.A. Berezinets, Electr. station, 7, 64 (1999)

6. O.Yu. Romashova, MATEC Web Conf. 91, 5 (2017)

7. O.Yu. Romashova, Y.A. Skrebatun, E.Ya. Sokolova, MATEC Web Conf. 19, 5 (2014)

8. A.G. Kostyuk, V.V. Frolov, Steam and Gas Turbines for power station (Publishing house MEI, Moscow, 2008) 